\title{
The Role of Gender in Cost-Related Medication Nonadherence Among Patients with Diabetes
}

\author{
Soumitra S. Bhuyan, PhD, MPH, Olayinka Shiyanbola, PhD, BPharm, \\ Pallav Deka, MS, PhD, AGACNP-BC, Oluwaseyi O. Isehunwa, PhD, MPH, \\ Aastha Chandak, PhD, Sean Huang, PhD, Yang Wang, PhD, \\ Jay Bhatt, DO, MPH, MPA, Lu Ning, PhD, Wang Jun Lin, PhD, David Wyant, PhD, \\ Satish Kedia, PhD, and Cyril F. Chang, PhD
}

Objective: Under $50 \%$ of type 2 diabetic patients achieve the recommended glycemic control. One barrier to glycemic control is patients' cost-related nonadherence to medications. We hypothesize gender differences in medication nonadherence due to costs among diabetic patients.

Methods: US National Health Interview Survey (2011 to 2014) data yielded 5260 males and 6188 females with diabetes for over a year. We applied 2 analytic methods (A and B below) across multiple outcome measures ( 1 to 4 ) of medication nonadherence due to cost. The key independent variable was participant's gender.

Results: Across methods and measure, females consistently report significantly higher rates of medication nonadherence due to costs. Pearson's $\chi^{2}$ showed that female patients were more likely to (1) skip medication $(13.5 \%-10.2 \% ; P<.001)$, take less than prescribed medication $(13.9 \%-10.5 \% ; P<$ $.001)$, delay filling prescriptions $(16.8 \%-12.5 \% ; P<.001)$, and ask doctors to prescribe lower-cost alternative medications $(31.8 \%-28.0 \% ; P<.001)$. Controlling for covariates, logistic regression models found females more likely to skip medication (OR, 1.30; 95\% CI, 1.09-1.55), take less than prescribed medication (OR, 1.26; 95\%, CI, 1.06-1.50), delay filling prescriptions, (OR, 1.29; 95\% CI, 1.11-1.50), and request lower-cost medication (OR, 1.17; 95\% CI, 1.04-1.32). Our results report other factors that influence medication adherence, including socioeconomic and health status variables.

Conclusions: A significant gender-based disparity exists on cost-related nonadherence of medication among diabetic patients. Health care providers and policy-makers should pay close attention to find ways to address cost-related nonadherence of medication among patients with chronic illness, especially among female patients. (J Am Board Fam Med 2018;31:743-751.)

Keywords: Blood Glucose; Diabetes Mellitus; Drug Costs; Health Expenditures; Medication Adherence; Outcome Measure

Diabetes continues to be a significant public health concern both in developing and developed countries. Currently, over 400 million people are living

This article was externally peer reviewed.

Submitted 3 February 2018; revised 30 May 2018; accepted 5 June 2018.

From School of Public Health, The University of Memphis, Memphis, TN (SSB, OOI, SK); School of Pharmacy, University of Wisconsin, Madison, WI (OS); Department of Nursing, University of South Dakota, Sioux Falls, SD (PD); Analytica Laser, New York, NY (AC); Department of Health Systems Administration, Georgetown University, Washington D.C. (SH); Joseph J. Zilber School of Public Health, University of Wisconsin-Milwaukee, WI (YW); Health Research and Educational Trust, Chicago, IL (JB); Department of Health Administration, Governor State with diabetes worldwide, and about 640 million people are at risk of developing diabetes. ${ }^{1}$ In 2012, there were 1.5 million deaths due to diabetes and another 2.2 million deaths from diseases related to

University, IL (LN); Department of Clinical Pharmacy, University of Tennessee Health Sciences Center, TN (WJL); Jack C. Massey College of Business, Belmont University, TN (DW); Fogelman College of Business and Economics, The University of Memphis, Memphis, TN (CFC).

Funding: none.

Conflict of interest: none declared.

Corresponding author: Soumitra S. Bhuyan, PhD, MPH, Division of Health Systems Management and Policy, The University of Memphis, 135 Robison Hall, Memphis, TN 38152 (E-mail: sbhuyan@memphis.edu). 
prediabetes conditions worldwide. ${ }^{2}$ Diabetes is expected to be the seventh leading cause of death worldwide by $2030 .^{2}$ In the United States, an estimated $9.4 \%$ of the adult population has diabetes, including 30.3 million diagnosed and 8.1 million undiagnosed adults. ${ }^{3}$ Diabetes is also a significant contributor to health care costs in the United States, with an estimated nondiscounted lifetime spending of $\$ 211,400$ for the treatment of diabetes diagnosed at age 40 years. ${ }^{4}$

To prevent diabetes complications and reduce diabetes-related mortality, it is recommended that patients achieve glycemic control at a hemoglobin A1C value of $<7.0 \%{ }^{5}$ However, literature has shown that less than $50 \%$ of patients with type 2 diabetes are able to achieve the recommended glycemic control value. ${ }^{6}$ One of the major barriers to achieving the desired glycemic control is patients' nonadherence to diabetes medications. ${ }^{6-8}$ Patients are deemed adherent if they take their medications as prescribed $80 \%$ of the time. ${ }^{9,10}$ A systematic review reported that adherence to oral hypoglycemic agents ranged between $36 \%$ and $93 \%$ among patients with diabetes receiving treatment for 6 to 24 months. ${ }^{7}$ It has been shown that adherence to medications can effectively reduce diabetes-associated morbidity and mortality. ${ }^{11}$ Medication adherence also plays a significant role in reducing the total health care costs for managing diabetes. ${ }^{8,12-16}$ It is estimated that a $10 \%$ increase in diabetes medication adherence would lead to a $6.6 \%$ decrease in hospitalizations for diabetes-related complications. ${ }^{17}$

Medication nonadherence has been found to be associated with a complex set of factors, including socioeconomic (ethnicity, income, and social support), personal preference (patient treatment and illness beliefs and medication safety concerns), and medication-related issues (complex dosing regimens and polypharmacy). ${ }^{6,13,18,19}$ Other factors associated with medication nonadherence include depression, ${ }^{20}$ food insecurity, ${ }^{21}$ patient mood, ${ }^{22,23}$ and doctor-patient discordance. ${ }^{24}$ Many of these factors, when combined with the cost of medication can lead to further nonadherence among diabetic patients. ${ }^{13,16}$ In a survey of US adults with type 2 diabetes receiving blood glucose-lowering therapy, $11 \%$ indicated that they had limited their medication intake in the past year due to cost. In addition, $7 \%$ had cut back their medications in the past month. ${ }^{25}$
Specific gender-related differences have been linked to medication nonadherence for various chronic diseases. Studies have found lower adherence among females than males to antiretroviral medications, ${ }^{26}$ statin therapy, ${ }^{27}$ and medications for hypertension and hyperlipidemia. ${ }^{28}$ Although medication nonadherence has been found to be higher in the uninsured, underinsured, and among the elderly, ${ }^{29,30}$ being female has been found to be a major determinant of cost-related medication nonadherence (CRN) among cancer survivors. ${ }^{15,28,35}$ Among patients with diabetes, it is less clear whether medication cost affects males and females differently in their adherence behavior to prescribed medications. However, it is likely that the pattern of genderrelated differences in medication nonadherence for patients with diabetes will vary from nonadherence for patients with other diseases. In addition, there could also be differences in expectations concerning both the cost and benefits of adherence for patients with diabetes. With respect to expectations regarding the benefits of continuing with their medications, patients with diabetes will likely have different estimates of both the likelihood and severity of possible health effects of nonadherence. The costs of continuing to adhere are also probably different. The cost of diabetes medication will differ from the cost of drugs for other diseases, and the total cost of medications will differ to the extent that patients with diabetes may be taking multiple drugs for effective control of blood sugar levels. There are also possible differences in the pattern of insurance coverage and transaction costs (eg, some drugs require more frequent trips to the pharmacy for refills). At least some of these factors are likely to impact males differently than females (eg, higher prices are more difficult for lower income individuals). Consequently, for patients with diabetes, we are likely to find a different pattern of gender-related differences in medication adherence.

The purpose of this study was to investigate if there is a gender difference in medication nonadherence due to costs among patients with diabetes. Specifically, the study sought to determine whether, when compared with male patients, to save money, female diabetic patients are (1) more likely to skip taking their medication, (2) more likely to take less medication, (3) more likely to 
delay filling their prescription, (4) and more likely to request their doctor to prescribe lowercost medications.

\section{Methods \\ Data}

We analyzed 4 years of data (2011 to 2014) drawn from information collected by the US National Health Interview Survey (NHIS). ${ }^{31}$ Maintained by the National Center for Health Statistics, the NHIS is an annual cross-sectional household survey administered to civilian noninstitutionalized population residing in the United States at the time of the interview. The NHIS survey adult sample is nationally representative of the adult population in the United States and is obtained by using a stratified multistage probability sampling method with unequal probabilities of selection to purposefully oversample specific subgroups of people, including racial/ethnicity minorities. ${ }^{32}$ A complex survey design was adjusted in our data analysis to obtain nationally representative estimates. For our study, there were 13,326 respondents living with diabetes for more than a year in the source population. Approximately 5\% of them (662) had not been prescribed with any medications within the past 12 months. After the listwise deletion, our final analytic sample included 5260 males and 6188 females. There was no significant difference between gender in the percentages of respondents removed from the sample $(P=.306)$.

\section{Variables}

\section{Dependent Variables}

The outcome variable of interest were 4 categories of nonadherence to medications due to cost concerns: (1) skipped medication, (2) took less medication, (3) delayed prescription filling, and (4) requested lower cost medication. All 4 outcome variables were measured by a response to a set of the survey questions that asked, "During the past 12 months, were any of the following true for you?: you skipped medication doses to save money, you took less medication to save money, you delayed filling a prescription to save money, and you asked your doctor for a lower cost medication to save money."

The response options for each of the 4 behavioral outcomes were "yes" or "no," with a "yes" indicating an outcome of CRN.

\section{Independent Variables}

The key independent variable of interest was the gender of the participant, which was categorized as "male" or "female." The Andersen's Behavioral Model of Health Services Utilization was used as the theoretical framework to identify other pertinent independent variables related to predisposing, enabling, and need determinants. ${ }^{33,34}$ Our predisposing factors included demographic and sociocultural factors such as respondents' age, gender, race/ ethnicity, and marital status that may predispose an individual's behavior in seeking health services. We categorized age into 4 groups of 18 to 29 years, 30 to 44 years, 45 to 64 years, and 65 years and above. Marital status was dichotomized as married versus nonmarried. Respondent's race/ethnicity was categorized as non-Hispanic white, non-Hispanic black, Hispanic, and non-Hispanic others.

Enabling factors are the resources that are available to a person to be able to seek health care. Enabling factors in this study included whether or not the respondent had a usual source of care, respondents' education, health insurance status, and poverty level. The educational level of a respondent is measured by the highest level of education achieved, which is categorized as less than high school, high school, and some college and above. We categorized respondents' health insurance status into 3 groups of no insurance, private insurance, and public insurance. Poverty level was measured by a poverty-income ratio determined by the ratio of family income to the poverty threshold for a family of that size. Respondents were categorized as poor (ratio $<1$ ), near poor (ratio 1 to 2 ), and nonpoor (ratio $>2$ ).

Finally, need factors refer to an individual's health status or any medical problems that they may have faced and perceived need of seeking health care services. In this study, 2 major groups of need factors were identified: health status and health behavior of study participants. Health status factors included respondents' self-reported health and functional limitation status. Self-reported health was categorized as "good and above" (good, very good, and excellent) and "fair and below" (fair and poor). Functional limitation was dichotomized into not limited in any way versus having a functional limitation. Health behavior-related factors included smoking status categorized as current smoker or not a current smoker and alcohol use 
categorized as heavy use (heavy or medium users) and light use (light or nondrinkers). We coded "Refused," "Not ascertained,", or "Do not know" as missing for all the variables in the analyses.

\section{Analysis}

Using the individual respondent as a unit of analysis, we first conducted univariate analysis to examine the sample characteristics of the study. Pearson's $\chi^{2}$ tests were performed to compare the differences in CRN behaviors and covariates between males and females. We then used multivariate logistic regressions to model the association between patient's gender and nonadherence to medications due to cost concerns, controlling for other covariates. The 4 dependent variables used in the multiple logistic regression models were the following: (1) skipped medication, (2) took less medication, (3) delayed prescription filling, and (4) asked for a lower-cost medication. All statistical analyses were performed using Stata SE 13.0 with weighted estimates being reported (College Station, Texas, USA).

\section{Results}

Table 1 shows the characteristics of the analytic sample included in this study. Of the 11,448 study participants, $11.8 \%$ skipped medication, $12.2 \%$ took less medication, $14.6 \%$ delayed filling their prescriptions, and $29.9 \%$ asked their doctor for a lower-cost medication to save money in the past 12 months. In terms of patient characteristics, $95.8 \%$ reported having a place to go for medical attention when needed and about $87 \%$ were 45 years of age or older. About $62.9 \%$ of the respondents were non-Hispanic white, $15.1 \%$ were non-Hispanic black, $15.1 \%$ were Hispanic, and $6.9 \%$ were nonHispanic others. The majority of respondents had an education level of high school or more (91.0\%) and had either public or private insurance (91.5\%). A little more than half (57.3\%) were nonmarried. Only $8.5 \%$ of the sample did not have private or public insurance coverage. About $16.4 \%$ of the respondents were below the poverty level and 39.6\% of them reported their health to be fair or poor.

Gender-based differences in adherence behavior due to cost-related medication are also shown in Table 1. For example, $10.2 \%$ of males responded that they skipped medication due to cost-related concerns and $13.5 \%$ of females also responded to the same. A higher proportion of females (13.9\%) than males $(10.5 \%)$ reported taking less medication due to costs. Among patients who delayed filling a prescription due to cost-related reasons, the proportion of females were higher than that of males, with $16.8 \%$ versus $12.5 \%$, respectively. Finally, consistent with the descriptive results of the first 3 nonadherent behaviors, females' nonadherence rates were slightly higher than the males' rate (31.8\% vs $28.0 \%$ ) among patients who asked for lower-cost medication. All the differences between males and females were statistically significant $(P<.001)$.

Table 2 reports the results of 4 logistic regression models on nonadherent behaviors. The first column shows that females were more likely (OR, 1.30; 95\% CI, 1.09-1.55) to skip medication compared with males. Among the enabling and need factors, patients were more likely to skip medication if they were younger, poorer, had no health insurance, were smokers, reported poor health status, had functional limitations, or had no usual source of care. The second column of Table 2 indicates the likelihood of taking less medication because of cost and female patients were more likely (OR, 1.26; $95 \%$ CI, 1.06-1.50) than males to take less than prescribed medication. Among the enabling and need factors, patients were more likely to take less medication if they were younger, poorer, had no health insurance, were smokers, reported poor health status, had functional limitations, or had no usual source of care. The third column shows that female patients were more likely (OR, 1.29; 95\% CI, 1.11-1.50) to delay filling prescriptions due to cost concerns than males. Similar to the other 3 models, patients were more likely to delay filling their prescription if they were younger, poorer, had no health insurance, were smokers, or reported poor health status, had functional limitations, or no usual source of care. The fourth column shows that females were found more likely (OR, 1.17; 95\% CI, 1.04-1.32) to ask their doctor to prescribe lower-cost alternative medication than males and this was also statistically significant. Among the covariates, patients were more likely to request low-cost alternatives if they were less than age 65 , non-Hispanic white, had no health insurance, were not in poverty, reported poor health status, or had functional limitations. 
Table 1. Analytical Sample Description in Percentages (Unweighted Sample $N=11,448$ )

\begin{tabular}{|c|c|c|c|c|c|}
\hline Variables & No. & All Participants & Males & Females & $P$ Values \\
\hline Skipped medication & 1,349 & $11.8(11.1-12.6)$ & $10.2(9.2-11.3)$ & $13.5(12.4-14.7)$ & $<.001$ \\
\hline Took less medication & 1,413 & $12.2(11.5-13.0)$ & $10.5(9.5-11.6)$ & $13.9(12.8-15.1)$ & $<.001$ \\
\hline Delayed filling prescription & 1,671 & $14.6(13.8-15.5)$ & $12.5(11.4-13.6)$ & $16.8(15.6-18.1)$ & $<.001$ \\
\hline Lower-cost medication & 3,281 & $29.9(28.8-31.0)$ & $28.0(26.4 .29 .6)$ & $31.8(30.2-33.4)$ & $<.001$ \\
\hline \multicolumn{6}{|l|}{ Usual source of care } \\
\hline Yes & 10,940 & $95.8(95.4-96.3)$ & $95.5(94.8-96.1)$ & $96.2(95.6-96.7)$ & .135 \\
\hline No & 508 & $4.2(3.7-4.6)$ & $4.5(3.9-5.2)$ & $3.8(3.3-4.4)$ & \\
\hline \multicolumn{6}{|l|}{ Age-y } \\
\hline 18 to 29 & 232 & $2.5(2.1-2.9)$ & $2.0(1.6-2.6)$ & $2.9(2.4-3.6)$ & .006 \\
\hline 30 to 44 & 1,098 & $10.2(9.5-10.9)$ & $9.9(8.9-10.9)$ & $10.5(9.5-11.5)$ & \\
\hline 45 to 64 & 4,988 & $47.3(46.0-48.5)$ & $49.3(47.4-51.1)$ & $45.3(43.5-47.1)$ & \\
\hline 65 and above & 5,130 & $40.1(38.8-41.3)$ & $38.8(37.1-40.6)$ & $41.3(39.6-43.0)$ & \\
\hline \multicolumn{6}{|l|}{ Race/ethnicity } \\
\hline Non-Hispanic white & 6,351 & $62.9(61.6-64.2)$ & $64.8(63.0-66.6)$ & $60.9(59.3-62.6)$ & $<.001$ \\
\hline Non-Hispanic black & 2,262 & $15.1(14.2-16.1)$ & $13.3(12.2-14.5)$ & $17.0(15.8-18.2)$ & \\
\hline Hispanic & 1,982 & $15.1(14.1-16.2)$ & $15.0(13.6-16.6)$ & $15.1(14.0-16.3)$ & \\
\hline Non-Hispanic other & 853 & $6.9(6.3-7.6)$ & $6.8(6.0-7.7)$ & $7.0(6.1-7.9)$ & \\
\hline \multicolumn{6}{|l|}{ Education attainment } \\
\hline Less than high school & 1,240 & $9.1(8.4-9.8)$ & $8.1(7.2-9.1)$ & $10.0(9.1-10.9)$ & $<.001$ \\
\hline High school & 4,863 & $42.3(41.0-43.5)$ & $41.2(39.4-43.1)$ & $43.3(41.7-44.9)$ & \\
\hline Some college and above & 5,345 & $48.7(47.3-50.0)$ & $50.6(48.7-52.5)$ & $46.7(45.1-48.3)$ & \\
\hline \multicolumn{6}{|l|}{ Marital status } \\
\hline Married & 4,984 & $57.3(56.1-58.6)$ & $67.3(65.7-68.8)$ & $47.3(45.4-49.2)$ & $<.001$ \\
\hline Nonmarried & 6,464 & $42.7(41.4-43.9)$ & $32.7(31.2-34.3)$ & $52.7(50.8-54.6)$ & \\
\hline \multicolumn{6}{|l|}{ Health insurance } \\
\hline Private & 5,333 & $51.6(50.2-53.0)$ & $53.8(52.0-55.6)$ & $49.4(47.5-51.3)$ & .001 \\
\hline Public & 5,149 & $39.9(38.6-41.2)$ & $37.9(36.3-39.5)$ & $41.9(40.1-4.37)$ & \\
\hline No coverage & 966 & $8.5(7.9-9.2)$ & $8.3(7.4-9.3)$ & $8.7(7.9-9.6)$ & \\
\hline \multicolumn{6}{|l|}{ Poverty ratio } \\
\hline Less than 1 & 2,482 & $16.4(15.5-17.3)$ & $13.1(12.0-14.2)$ & $19.7(18.4-21.0)$ & $<.001$ \\
\hline 1 to 2 & 2,869 & $22.8(21.7-23.9)$ & $20.1(18.8-21.5)$ & $25.4(24.0-27.0)$ & \\
\hline Greater than 2 & 6,097 & $60.9(59.5-62.2)$ & $66.8(65.1-68.5)$ & $54.9(53.1-56.7)$ & \\
\hline \multicolumn{6}{|l|}{ Self-reported health } \\
\hline Good and above & 6,699 & $60.4(59.2-61.6)$ & $62.4(60.7-64.2)$ & $58.4(56.8-60.1)$ & .001 \\
\hline Fair and below & 4,749 & $39.6(38.4-40.8)$ & $37.6(35.8-39.3)$ & $41.6(39.9-43.2)$ & \\
\hline \multicolumn{6}{|l|}{ Current smoker } \\
\hline Yes & 1,809 & $15.2(14.3-16.1)$ & $16.4(15.1-17.7)$ & $14.0(13.0-15.2)$ & .004 \\
\hline No & 9,639 & $84.8(83.9-85.7)$ & $83.6(82.3-84.9)$ & $86.0(84.8-87.0)$ & \\
\hline \multicolumn{6}{|l|}{ Alcohol use } \\
\hline Heavy \& medium & 1,078 & $10.1(9.4-10.9)$ & $15.5(14.3-16.8)$ & $4.8(4.1-5.6)$ & $<.001$ \\
\hline Light \& no use & 10,370 & $89.9(89.1-90.6)$ & $84.5(83.2-85.7)$ & $95.2(94.4-95.9)$ & \\
\hline \multicolumn{6}{|l|}{ Functional limitation } \\
\hline Not limited in any way & 3,382 & $32.2(31.1-33.3)$ & $38.6(36.8-40.3)$ & $25.8(24.4-27.2)$ & $<.001$ \\
\hline Has a functional limitation & 8,066 & $67.8(66.7-68.9)$ & $61.4(59.7-63.2)$ & $74.2(72.8-75.6)$ & \\
\hline
\end{tabular}

All values are in percentages. Values within parenthesis indicate $95 \%$ Confidence Intervals.

\section{Discussion}

The purpose of this study was to examine the association between gender and CRN among patients with diabetes. We used multiple methods $\left(\chi^{2}\right.$, logistic regression) across multiple measures (skipped, took less, delayed, requested low-cost alternative medications) and our results consistently found that females were associated with CRN 
Table 2. Multivariate Logistic Regression Models for Association between Gender and Cost-Related Medication Nonadherence among Diabetes Patients $(\mathrm{N}=11,448)$

\begin{tabular}{|c|c|c|c|c|}
\hline & $\begin{array}{c}\text { Skipped } \\
\text { Medication } \\
\text { OR (95\% CI) }\end{array}$ & $\begin{array}{c}\text { Took Less } \\
\text { Medication } \\
\text { OR (95\% CI) }\end{array}$ & $\begin{array}{l}\text { Delayed Filling } \\
\text { Prescription } \\
\text { OR }(95 \% \text { CI) }\end{array}$ & $\begin{array}{c}\text { Lower-Cost } \\
\text { Medication } \\
\text { OR (95\% CI) }\end{array}$ \\
\hline \multicolumn{5}{|l|}{ Gender } \\
\hline Male (Ref) & 1.00 & 1.00 & 1.00 & 1.00 \\
\hline Female & $1.30^{* *}(1.09-1.55)$ & $1.26^{*}(1.06-1.50)$ & $1.29^{* * *}(1.11-1.50)$ & $1.17^{* *}(1.04-1.32)$ \\
\hline \multicolumn{5}{|l|}{ Usual Source of Care } \\
\hline Yes & $0.59^{* * *}(0.44-0.79)$ & $0.56^{\star * *}(0.42-0.74)$ & $0.60^{\star * *}(0.45-0.79)$ & $1.09(0.84-1.42)$ \\
\hline No (Ref) & 1.00 & 1.00 & 1.00 & 1.00 \\
\hline \multicolumn{5}{|l|}{ Age } \\
\hline 18 to 29 (Ref) & 1.00 & 1.00 & 1.00 & 1.00 \\
\hline 30 to 44 & $0.99(0.63-1.54)$ & $1.05(0.68-1.63)$ & $1.13(0.72-1.76)$ & $1.28(0.88-1.87)$ \\
\hline 45 to 64 & $0.73(0.48-1.12)$ & $0.80(0.53-1.21)$ & $0.75(0.48-1.16)$ & $1.06(0.74-1.50)$ \\
\hline 65 and above & $0.24^{* * *}(0.15-0.38)$ & $0.29^{* * *}(0.19-0.46)$ & $0.28^{* * *}(0.18-0.44)$ & $0.69^{*}(0.48-0.99)$ \\
\hline \multicolumn{5}{|l|}{ Race/Ethncity } \\
\hline Non-Hispanic White (Ref) & 1.00 & 1.00 & 1.00 & 1.00 \\
\hline Non-Hispanic Black & $1.12(0.92-1.37)$ & $1.20(0.99-1.46)$ & $1.09(0.91-1.30)$ & $0.80^{* *}(0.69-0.92)$ \\
\hline Hispanic & $1.02(0.81-1.28)$ & $0.99(0.78-1.24)$ & $0.85(0.68-1.06)$ & $0.72^{* * *}(0.60-0.85)$ \\
\hline Non-Hispanic Other & $0.61^{* *}(0.42-0.89)$ & $0.63 *(0.43-0.92)$ & $0.50^{\star * *}(0.35-0.71)$ & $0.64^{* * *}(0.50-0.81)$ \\
\hline \multicolumn{5}{|l|}{ Education Attainment } \\
\hline Less than High School (Ref) & 1.00 & 1.00 & 1.00 & 1.00 \\
\hline High School & $1.18(0.88-1.58)$ & $1.25(0.93-1.68)$ & $1.06(0.81-1.39)$ & $1.12(0.90-1.39)$ \\
\hline Some College and Above & $1.36(0.99-1.86)$ & $1.53^{* *}(1.12-2.09)$ & $1.17(0.87-1.58)$ & $1.21(0.96-1.53)$ \\
\hline \multicolumn{5}{|l|}{ Marital Status } \\
\hline Married & $1.09(0.93-1.28)$ & $1.08(0.92-1.26)$ & $1.07(0.92-1.24)$ & $1.11(0.99-1.25)$ \\
\hline Non-married (Ref) & 1.00 & 1.00 & 1.00 & 1.00 \\
\hline \multicolumn{5}{|l|}{ Health Insurance } \\
\hline Private (Ref) & 1.00 & 1.00 & 1.00 & 1.00 \\
\hline Public & $0.74^{* *}(0.61-0.91)$ & $0.68^{* * *}(0.55-0.83)$ & $0.69^{* * *}(0.57-0.82)$ & $0.79^{* * *}(0.69-0.89)$ \\
\hline No Coverage & $2.72^{* * *}(2.10-3.53)$ & $2.46^{* * *}(1.91-3.17)$ & $2.26^{* * *}(1.79-2.83)$ & $2.11^{* * *}(1.73-2.58)$ \\
\hline \multicolumn{5}{|l|}{ Poverty Ratio } \\
\hline Less than 1 (Ref) & 1.00 & 1.00 & 1.00 & 1.00 \\
\hline 1 to 2 & $1.24(0.98-1.56)$ & $1.14(0.91-1.43)$ & $1.14(0.91-1.43)$ & $1.61^{* * *}(1.35-1.92)$ \\
\hline Greater than 2 & $0.62^{* * *}(0.46-0.82)$ & $0.55^{* * *}(0.42-0.71)$ & $0.59^{* * *}(0.46-0.76)$ & $1.30^{* *}(1.08-1.56)$ \\
\hline \multicolumn{5}{|l|}{ Self-reported Health } \\
\hline Good and above & $0.55^{* * *}(0.46-0.65)$ & $0.53^{* * *}(0.44-0.63)$ & $0.57^{* * *}(0.48-0.67)$ & $0.73^{* * *}(0.65-0.83)$ \\
\hline Fair and below (Ref) & 1.00 & 1.00 & 1.00 & 1.00 \\
\hline \multicolumn{5}{|l|}{ Current Smoker } \\
\hline Yes & $1.39^{* *}(1.14-1.70)$ & $1.36^{* *}(1.12-1.64)$ & $1.28^{*}(1.06-1.54)$ & $1.12(0.97-1.30)$ \\
\hline No (Ref) & 1.00 & 1.00 & 1.00 & 1.00 \\
\hline \multicolumn{5}{|l|}{ Alcohol Use } \\
\hline Heavy \& Medium & $1.05(0.80-1.37)$ & $0.94(0.72-1.22)$ & $0.83(0.64-1.09)$ & $0.86(0.71-1.05)$ \\
\hline Light \& No use (Ref) & 1.00 & 1.00 & 1.00 & 1.00 \\
\hline \multicolumn{5}{|l|}{ Functional Limitation } \\
\hline Not limited in any way (Ref) & 1.00 & 1.00 & 1.00 & 1.00 \\
\hline Has a functional limitation & $1.90^{* * *}(1.55-2.33)$ & $2.01^{* * *}(1.65-2.46)$ & $1.98^{* * *}(1.65-2.38)$ & $1.67^{* * *}(1.46-1.92)$ \\
\hline
\end{tabular}

CI, confidential interval; OR, odd ratio.

${ }^{*} P<.05$.

${ }^{*} P<.01$.

$* * * P<.001$.

Regression adjusted for survey year. 
among patients with diabetes. Due to cost concerns, female patients with diabetes were significantly more likely to skip medication, take less medication, delay filling their prescription, and ask for lower-cost medication compared with their male counterparts. These findings are consistent with other studies that have reported gender differences in patients with other chronic conditions. ${ }^{26,27,28,35}$

This study adds new knowledge to the current literature in that it highlights the fact that the cost of medication affects females more than males with diabetes. Costs create a significant barrier among female patients adhering to their medication. Gender-based differences in self-care activities have been reported among patients with diabetes. ${ }^{36} \mathrm{Be}$ cause adherence is largely a self-care activity, our study contributes to the knowledge regarding selfcare activities that are important to health outcomes for patients.

The results also suggest that nonadherence to medication could be lower for individuals on public insurance than for individuals on private insurance. This is true for all 4 logistic models. Because nonadherence increases the cost of care, this suggests that private insurance companies may want to provide stronger incentives and review policies that are effective in enhancing medication adherence, such as patient education, adherence follow-up, and cost sharing for chronic diseases. The large differences in adherence between the uninsured (which reported much higher levels of nonadherence) and those on public insurance suggest that increased insurance coverage could help increase adherence and, in turn, reduce the overall health care cost for patients with diabetes in the United States. Similarly, in all 4 logistic models, those in the near poor group reported lower medication adherence rates compared with individuals in poverty. This could be because the near poor group may be more likely to be excluded from social assistance programs.

Furthermore, the findings in our results that other factors related to CRN are consistent with previous studies on nonadherence to medication in patients with diabetes. ${ }^{6,13} \mathrm{CRN}$ among diabetic patients with Medicare Part D beneficiaries has been reported. ${ }^{37}$ As such, CRN is existent even among patients who have insurance. Similar results have also been observed in a study published using the National Health Survey data. This study found that among stroke survivors, along with being female, other factors such as lower health status, high comorbidity score, greater poverty, not having health insurance, and functional limitations were associated with CRN. ${ }^{38}$ Based on other studies and findings from our present study, it is evident that addressing the risk factors for CRN should not only address insurance or income factors but also consider gender to be a significant risk factor for medication nonadherence.

In a discussion of the problem of lower rates of adherence for statins among females and minorities, Lewey et al. ${ }^{27}$ summarized a number of general approaches toward improving adherence, which would be of interest in our case. They suggest a combination of patient education, medication reminders, and reinforcement. They note that the increased use of electronic medical records creates the possibility of more timely information for providers. Medication nonadherence can lead to increased healthcare spending in the long run. As such, there may be value to payers in rethinking their net cost of providing (or not providing) these drugs and the cost-effectiveness of programs to enhance adherences. ${ }^{39-41}$

Although we found significant gender differences in CRN among patients with diabetes, it is not clear what causes the gender differences. Interestingly, our results were robust after controlling for insurance coverage, education attainment, economic status, and other extensive control variables. We propose several plausible hypotheses may be warranted to be explored in future studies. First, the progression and severity of diabetes may be systematically different between males and females. Second, although we control for both insurance coverage and poverty status, gender difference may exist in preferences and attitudes toward medical spending over other living expenses. In addition, it is found that greater perceived financial stress and food insecurity are associated with higher likelihoods of CRN. ${ }^{42,43}$ Jianakoplos et al. ${ }^{44}$ and Powel et al. $^{45}$ have reported that females are more risk averse toward financial risks. ${ }^{44,45}$ Greater perceived financial stress and food insecurity may have higher likelihoods of nonadherence among females. Lastly, the dynamics and structures within the household can play an important role. In addition, the gender gap in earnings may provide males more autonomy of spending and, hence, explain the difference in medication noncompliance. ${ }^{41}$ 
Several limitations exist in this study. First, information collected by the NHIS survey is selfreported and recall bias may have been possible. However, given the sample size, unless the recall bias is systematic, our study results are less likely to be biased. Second, this study was based on crosssectional data of 4 years. Thus, the results of the study cannot infer causality. The study only focused on cost-related nonadherences to medication, and other factors, such as patient-provider communication, organizational factors, and psychological factors, that may affect medication nonadherence, were beyond the scope of our study. In addition, patients may be taking multiple drugs, so the fact that they are taking less medication does not always mean that they are nonadherent for diabetes medicine. Lastly, the study results are based on a representative sample of civilian noninstitutionalized adult population in the United States. Caution should be exercised when generalizing the study results to any other populations.

Our study indicates that female patients with diabetes may be at a higher risk of treatment failure due to medication nonadherence. $\mathrm{CRN}$ in patients with diabetes is different for males and females. For cost-related reasons, females are more likely to skip medications, take less medication, delay filling their prescription, and ask their doctors to prescribe lowcost medication. Clinicians should also note that this study reinforces the importance of the critical association between lack of insurance coverage and nonadherence. In addition, it is misleading to assume that cost of medication affects both genders similarly. Therefore, efforts to improve adherence to medication among patients with diabetes should take both medication costs and gender-related differences into account.

To see this article online, please go to: http://jabfm.org/content/ 31/5/743.full.

\section{References}

1. International Diabetes Federation. IDF Diabetes Atlas $-8^{\text {th }}$ Edition. Available from: http://www. diabetesatlas.org/. Accessed July 20, 2016.

2. World Health Organization. 10 Facts About Diabetes. 2016. Available from: http://www.who.int/ features/factfiles/diabetes/en/. Accessed July 24, 2016.

3. Centers for Disease Control and Prevention. National Diabetes Statistics Report. 2017; Available from https://www.cdc.gov/diabetes/pdfs/data/ statistics/national-diabetes-statistics-report.pdf. Accessed July 28, 2018.
4. Zhuo X, Zhang P, Barker L, et al. The lifetime cost of diabetes and its implications for diabetes prevention. Diabetes Care 2014;37:2557-64.

5. American Diabetes Association. Tight Diabetes Control. Available from: http://www.diabetes.org/ living-with-diabetes/treatment-and-care/bloodglucose-control/tight-diabetes-control.html? referrer=https://www.google.com/http://www. diabetes.org/living-with-diabetes/treatment-andcare/blood-glucose-control/tight-diabetes-control. html? referrer=https://www.google.com/. Accessed August 02, 2016.

6. Bailey CJ, Kodack M. Patient adherence to medication requirements for therapy of type 2 diabetes. Int J Clin Pract 2011;65:314-22.

7. Cramer JA. A systematic review of adherence with medications for diabetes. Diabetes Care 2004;27: $1218-24$.

8. Sokol MC, McGuigan KA, Verbrugge RR, et al. Impact of medication adherence on hospitalization risk and healthcare cost. Med Care 2005;43:521-30.

9. Cramer JA, Roy A, Burrell A, et al. Medication compliance and persistence: terminology and definitions. Value Health 2008;11:44-7.

10. Hansen RA, Kim MM, Song L, et al. Comparison of methods to assess medication adherence and classify nonadherence. Ann Pharmacother 2009;43:413-22.

11. DeFronzo RA. Pharmacologic therapy for type 2 diabetes mellitus. Ann Intern Med 1999;131:281303.

12. Breitscheidel L, Stamenitis S, Dippel FW, et al. Economic impact of compliance to treatment with antidiabetes medication in type 2 diabetes mellitus: a review paper. J Med Econ 2010;13:8-15.

13. García-Pérez LE, Álvarez M, Dilla T, et al. Adherence to therapies in patients with type 2 diabetes. Diabetes Ther 2013;4:175-94.

14. Ho PM, Rumsfeld JS, Masoudi FA, et al. Effect of medication nonadherence on hospitalization and mortality among patients with diabetes mellitus. Arch Intern Med 2006;166:1836-41.

15. Lee WC, Balu S, Cobden D, et al. Prevalence and economic consequences of medication adherence in diabetes: a systematic literature review. Manag Care Interface 2006;19:31-41.

16. Salas M, Hughes D, Zuluaga A, Vardeva K, Lebmeier M. Costs of medication nonadherence in patients with diabetes mellitus: a systematic review and critical analysis of the literature. Value Health 2009; 12:915-22.

17. Balkrishnan R, Rajagopalan R, Camacho FT, Huston SA, Murray FT, Anderson RT. Predictors of medication adherence and associated health care costs in an older population with type 2 diabetes mellitus: a longitudinal cohort study. Clin Ther $2003 ; 25: 2958-71$. 
18. Odegard PS, Gray SL. Barriers to medication adherence in poorly controlled diabetes mellitus. Diabetes Edu 2008;34:692-7.

19. Tarn DM, Heritage J, Paterniti DA, et al. Physician communication when prescribing new medications. Arch Intern Med 2006;166:1855-62.

20. Zivin K, Ratliff S, Heisler MM, et al. Factors influencing cost-related nonadherence to medication in older adults: a conceptually based approach. Value Health 2010;13:338-45.

21. Bengle R, Sinnett S, Johnson T, et al. Food insecurity is associated with cost-related medication non-adherence in community-dwelling, low-income older adults in Georgia. J Nutr Elder 2010;29:170-91.

22. Kurlander JE, Kerr EA, Krein S, et al. Cost-related nonadherence to medications among patients with diabetes and chronic pain factors beyond finances. Diabetes Care 2009;32:2143-8.

23. Piette JD, Rosland AM, Silveira MJ, et al. Medication cost problems among chronically ill adults in the US: did the financial crisis make a bad situation even worse. Patient Prefer Adherence 2011;5:187-94.

24. Jackson CA, Clatworthy J, Robinson A, et al. Factors associated with non-adherence to oral medication for inflammatory bowel disease: a systematic review. Am J Gastroenterol 2010;105:525-39.

25. Piette JD, Heisler M, Wagner TH. Problems paying out-of-pocket medication costs among older adults with diabetes. Diabetes Care 2004;27:384-91.

26. Puskas CM, Forrest JI, Parashar S, et al. Women and vulnerability to HAART non-adherence: a literature review of treatment adherence by gender from 2000 to 2011. Curr HIV/AIDS Rep 2011;8:277-87.

27. Lewey J, Shrank WH, Bowry AD, et al. Gender and racial disparities in adherence to statin therapy: a meta-analysis. Am Heart J 2013;165:665-78.

28. Rolnick SJ, Pawloski PA, Hedblom BD, et al. Patient characteristics associated with medication adherence. Clin Med Res 2013;11:54-65.

29. Kennedy J, Morgan S. Cost-related prescription nonadherence in the United States and Canada: a system-level comparison using the 2007 International Health Policy Survey in Seven Countries. Clin Ther 2009;31:213-9.

30. Soumerai SB, Pierre-Jacques M, Zhang F, et al. Cost-related medication nonadherence among elderly and disabled Medicare beneficiaries: a national survey 1 year before the medicare drug benefit. Arch Intern Med 2006;166:1829-35.

31. National Health Interview Survey. Available from: http://www.cdc.gov/nchs/nhis/. Accessed July 21, 2016.
32. Centers for Disease Control and Prevention, $\mathrm{Na}$ tional Health Interview Survey. Available from: http://www.cdc.gov/nchs/nhis/index.htm. Accessed August 2, 2018.

33. Aday LA, Andersen RM. Equity of access to medical care: a conceptual and empirical overview. Med Care. 1981;19:4-27.

34. Andersen R, Newman JF. Societal and individual determinants of medical care utilization in the United States. Millbank Q 2005;83.

35. Lee M, Khan MM. Gender differences in cost-related medication non-adherence among cancer survivors. J Cancer Surviv 2016;10:384-93.

36. McCollum M, Hansen LB, Lu L, et al. Gender differences in diabetes mellitus and effects on selfcare activity. Gend Med 2005;2:246-54.

37. Williams J, Steers WN, Ettner SL, et al. Costrelated nonadherence by medication type among Medicare Part D beneficiaries with diabetes. Med Care 2013;51:193.

38. Levine DA, Morgenstern LB, Langa KM, et al. Recent trends in cost-related medication nonadherence among stroke survivors in the United States. Ann Neurol 2013;73:180-8.

39. Morello CM, Hirsch JD. Strategies for addressing the cost of nonadherence in diabetes. Am J Manag Care 2017;23:S247-52.

40. Weeks G, George J, Maclure K, Stewart D. Nonmedical prescribing versus medical prescribing for acute and chronic disease management in primary and secondary care. Cochrane Database Syst Rev 2016 Jul 22(7).

41. Kymes SM, Pierce RL, Girdish C, Matlin OS, Brennan T, Shrank WH. Association among change in medical costs, level of comorbidity, and change in adherence behavior. Am J Manag Care 2016;22: e295-301.

42. Patel MR, Piette JD, Resnicow K, et al. Social determinants of health, cost-related nonadherence, and cost-reducing behaviors among adults with diabetes: findings from the National Health Interview Survey. Med Care 2016;54:796-803.

43. Blumberg DM, Prager AJ, Liebmann JM, Cioffi GA, De Moraes CG. Cost-related medication nonadherence and cost-saving behaviors among patients with glaucoma before and after the implementation of Medicare Part D. JAMA Ophthalmol 2015;133:985-96.

44. Jianakoplos NA, Bernasek A. Are women more risk averse? Econ Inq 1998;36:620-30.

45. Powell M, Ansic D. Gender differences in risk behaviour in financial decision-making: an experimental analysis. J Econ Psychol 1997;18:605-28. 